This is the peer reviewed version of the following article

Coopman, Q., Hoose, C., Stengel, M. (2019). Detection of Mixed-Phase Convective Clouds by a Binary Phase Information From the Passive Geostationary Instrument SEVIRI. Journal of Geophysical Research: Atmospheres, 124,

which has been published in final form at

https://doi.org/10.1029/2018JD029772

This article may be used for non-commercial purposes in accordance with Willey Terms and Conditions for Use of Self-Archived Versions. 


\title{
Detection of mixed-phase convective clouds by a binary-phase information from the passive geostationary instrument SEVIRI
}

\author{
Q. Coopman ${ }^{1}$, C. Hoose ${ }^{1}$, M. Stengel ${ }^{2}$. \\ ${ }^{1}$ Institute of Meteorology and Climate Research, Karlsruhe Institute of Technology, Karlsruhe, Germany \\ ${ }^{2}$ Deutscher Wetterdienst (DWD), Offenbach, Germany
}

Key Points:

- The space-based instrument SEVIRI is used to observe the thermodynamic phase transition of clouds

- Under specific conditions, the retrieved droplet radius before glaciation is larger than the retrieved ice crystal radius after glaciation

- Mixed-phase clouds can be detected from a binary liquid/ice phase information

Corresponding author: Quentin Coopman, quentin. coopman@kit.edu 


\section{Abstract}

Between $-37^{\circ} \mathrm{C}$ and $0^{\circ} \mathrm{C}$, clouds are either liquid, ice or mixed-phase. Nearly all retrieval algorithms for passive instruments provide binary phase information - ice or liquid - making it difficult to retrieve mixed-phase cloud properties. Based on measurements from the geostationary space-based instrument Spinning Enhanced Visible and InfraRed Imager (SEVIRI), we show that the retrieved ice crystal effective radius is smaller than the liquid droplet effective radius for $48 \%$ of 230 analyzed cloud thermodynamic phase transitions - phase transition from liquid to ice of rising convective clouds - while ice crystals are expected to be larger than cloud droplets. We simulate mixed-phase cloud radiances with the numerical model Santa Barbara DISORT Atmospheric Radiative Transfer (SBDART) for which we compare simulated effective radius retrievals with observations. The phase retrieval algorithm from SEVIRI does not represent well mixed-phase clouds and categorizing clouds by only ice and liquid is not enough to accurately represent mixed-phase cloud optical properties. We conclude that the mixed-phase nature of clouds explains that retrieved cloud droplet radii are larger than ice crystal radii directly before and after the phase transition. However, from a cloud-tracking algorithm perspective, the variation of the effective radius enables the detection of mixed-phase convective clouds from binary phase information.

\section{Introduction}

Cloud droplets freeze homogeneously at $-37^{\circ} \mathrm{C}$ but for temperatures between $-37^{\circ} \mathrm{C}$ and $0^{\circ} \mathrm{C}$, super-cooled cloud droplets and ice crystals can be observed [Rauber and Tokay, 1991; Cober et al., 2001]. The temperature of glaciation of a cloud depends on different parameters, such as cloud altitudes, surface types, cloud droplet sizes, or pollution concentration [Rangno and Hobbs, 2001; Rosenfeld et al., 2011; Carro-Calvo et al., 2016; Zamora et al., 2018; Coopman et al., 2018]. Clouds can therefore be composed of either only cloud droplets - referred to as liquid clouds — or only ice crystals — referred to as ice clouds — or a combination of super-cooled liquid droplets and ice crystals — referred to as mixed-phase clouds [Korolev et al., $2017]$.

Field campaign measurements show that a high fraction of mixed-phase clouds is observed at middle and high latitudes [e.g., Fleishauer et al., 2002; Zuidema et al., 2005; Shupe et al., 2008; Noh et al., 2011, 2013]. Mixed-phase clouds have an impact on the atmospheric radiative profile and to some extend to the Earth's radiation budget [Fleishauer et al., 2002; Larson et al., 2006]. However, the properties driving their development remain poorly under- 
stood [Shupe et al., 2008]. For example, mixed-phase clouds are not well represented in global climate models [McCoy et al., 2016], their interactions with aerosols, their radiative [Hansen et al., 1997] and dynamical [Boers and Mitchell, 1994] effects, and their role in cloud electrification [Korolev et al., 2017] are still undetermined.

Active space-based instruments, such as Cloud Aerosol Lidar and Infrared Pathfinder Satellite Observations (CALIOP) [Winker et al., 2009], retrieve the vertical distribution of cloud properties and can differentiate between liquid, ice, and mixed-phase clouds. However, such instruments provide measurements only for a limited domain. Moreover, lidars can only provide a vertical profile measurements where the liquid phase signal dominates the ice phase signal in case of mixed-phase clouds due to their penetration depth [Zhang et al., 2010], and radars cannot identify the liquid phase when cloud droplets and ice crystals Doppler velocity spectra overlap [Huang et al., 2009].

Algorithms based on passive space-based instrument measurements, such as algorithms based on measurements from Spinning Enhanced Visible and InfraRed Imager (SEVIRI) [Schmetz et al., 2002], retrieve cloud-top properties from visible and infrared measurements and consider ice and liquid clouds. Therefore, mixed-phase clouds are not represented or correspond, at best, to an "undetermined category". An algorithm described by Riedi et al. [2010], based on Moderate Resolution Imaging Spectroradiometer (MODIS) [Platnick et al., 2003] and POLarization and Directionality of the Earth's Reflectances (POLDER) [Bréon and Colzy, 1999] measurements, retrieves a phase index between 0 and 200 for different degrees of confidence of liquid and ice phase, which provides more flexibility than a binary phase distribution, but mixed-phase clouds are still not represented. Pavolonis et al. [2005], by using an algorithm based on the comparison of brightness temperature differences between the 8.5 and $11 \mu m$ channels and the brightness temperature from $11 \mu \mathrm{m}$, provide a mixed-phase cloud category merged with supercooled water. New passive satellite algorithms use also the difference in brightness temperature from 8.5 and $11 \mu \mathrm{m}$, e.g., the Visible Infrared Imager Radiometer Suite (VIIRS) from the Joint Polar Satellite System (JPSS) [Kopp et al., 2014] and Advanced Himawari Imager onboard Himawari [Mouri et al., 2016], whereas the Advanced Baseline Imager (ABI) on Geostationary Operational Environmental Satellite-16 GOES-16 uses the two channels 8.4 and $12.3 \mu \mathrm{m}$ [Schmit et al., 2017].

Methods based on physical properties have also been developed to discriminate between liquid or ice phase for convective clouds. For example, Yuan et al. [2010] based their retrievals 
for a region on the vertical distribution of the particulate radius at cloud tops to determine where clouds are liquid, ice or mixed [Rosenfeld and Lensky, 1998]. For instance, this method has been used to retrieve aerosol impacts on convective-cloud glaciation temperature using CALIOP and MODIS instruments [Rosenfeld et al., 2011]. It is based on statistics and requires at least 100 pixels for each temperature bin. Therefore, it is not suitable for studying individual small clouds.

In this article, we investigate the temporal evolution of cloud-droplet and ice-crystal size from the passive space-based instrument SEVIRI at the cloud phase transition. We focus on two particular cases representative of $48 \%$ of 230 clouds for which the retrieved ice crystals are smaller than liquid droplets and we show that this feature can be used to identify an intermittent mixed-phase state of the cloud top.

\section{Data Set and Methods}

\subsection{Observations}

Cloud properties derived from geostationary measurements of the Spinning Enhanced Visible and Infrared Imager (SEVIRI) have been used in this study, i.e. data of the CLoud property dAtAset using SEVIRI dataset - edition 2 (CLAAS-2) [Stengel et al., 2014; Benas et al., 2017]. In particular, cloud mask, cloud-top temperature, cloud-top phase, cloud effective radius and cloud optical thickness, in pixel resolution of $3 \times 3 \mathrm{~km}^{2}$ at sub-satellite point and approximately $4 \times 5 \mathrm{~km}^{2}$ over Europe, are used with a temporal resolution of 15 minutes. While all algorithm details are given in Benas et al. [2017] and references therein, we summarize important aspects of the CLAAS-2 dataset in the following.

- SEVIRI measurements in the visible and near-infrared channels were re-calibrated following the methodology of Meirink et al. [2013] using Aqua MODIS measurements as reference.

- Cloud mask/detection is based on a series of spectral threshold tests as a function of illumination and surface types among other factors. The pixel-based cloud mask can thus result in one of the four classifications: cloud filled, cloud free, cloud contaminated or snow/ice contaminated. Further information can be found in Derrien and Le Gléau [2005] and Derrien [2013].

- For cloud-top pressure retrieval, the measurements in SEVIRI infrared channels are matched to clear-sky and cloudy simulations of these using the Radiative Transfer for TOVS [RT- 
TOV; Saunders et al., 1999; Matricardi et al., 2004] and ERA-Interim [Dee et al., 2011] as source for all required ancillary data. This approach is complemented with $\mathrm{H}_{2} \mathrm{O}$-IRW (infrared window) intercept method [Schmetz et al., 1993] and the radiance rationing method [Menzel et al., 1983]. The retrieved cloud-top pressure is converted to cloudtop temperature using the ERA-Interim profiles. More information is given in Stengel et al. [2014].

- Cloud-top phase determination is based on a number of spectral tests involving SEVIRI measurements at $6.2,8.7,10.8,12.0$, and $13.4 \mu \mathrm{m}$ and simulated clear and cloudy sky radiances using RTTOV. This results in one of the following cloud types: liquid, supercooled, opaque ice, cirrus, overlap or overshooting, which are then further converted to a binary cloud phase [Benas et al., 2017]. It is important to note that, even if the $10.8 \mu \mathrm{m}$ channel is used to retrieve the cloud top phase and temperature, the two cloud products are mostly independent [Benas et al., 2017].

- The retrieval of effective radius and optical thickness is based on the Cloud Physical Properties (CPP) algorithm [Roebeling et al., 2006; Meirink and van Zadelhoff, 2016] using SEVIRI visible $(0.6 \mu \mathrm{m})$ and near-infrared $(1.6 \mu \mathrm{m})$ measurements and following the classical Nakajima and King [1990] approach. Required lookup tables of top-of-atmosphere reflectances were composed by simulations employing the Doubling-Adding KNMI radiative transfer model [Stammes, 2001]

Benas et al. [2017] also reported results of comprehensive evaluation studies: CLAAS2 cloud detection is characterized by a probability of detection (POD) score of $87.5 \%$. For cloud phase, POD scores of $91.6 \%$ and $74.9 \%$ are reported for liquid and ice phase, respectively. Higher uncertainties in cloud detection and cloud phase determination are present for optically very thin clouds (cloud optical thickness less than 0.2), while for thicker clouds the mentioned scores are significantly higher. Comparison with CALIOP further revealed very high Pearson correlation of greater than 0.84 for all cloud-top products. Comparison with MODIS shows good agreement of the cloud droplet effective radius $\left(r_{e}^{L i q}\right)$ but an overestimation of the ice crystal effective radius $\left(r_{e}^{I c e}\right)$ by CLAAS-2 [Benas et al., 2017].

For our analysis, we consider clouds between May and September, more favorable for convection, from 2012 to 2015 , over Europe - with latitudes between $37^{\circ} \mathrm{N}$ and $56^{\circ} \mathrm{N}$ and longitudes between $2^{\circ} \mathrm{W}$ and $24^{\circ} \mathrm{E}$. 


\subsection{Cloud tracking algorithm}

The tracking algorithm is based on the overlap of two successive cloud masks [Schröder et al., 2009]. The algorithm has three distinct steps.

(i) Firstly, we apply the cloud mask from the CLAAS-2 cloud product, considering only cloud filled pixel and cloud optical thickness $(\tau)$ greater than 0.3 . We define a cloud object as the aggregate of cloud filled pixels considering a 4-connectivity clustering algorithm from the binary cloud mask. We consider cloud objects with an area greater than $250 \mathrm{~km}^{2}$ and less than $12,500 \mathrm{~km}^{2}$ surrounded by clear sky to focus on convective clouds and to exclude large cirrus clouds.

(ii) Secondly, we apply the cloud mask to two temporally successive images 15 minutes apart. If cloud objects have an overlap greater than $50 \%$ and the area does not vary more than $50 \%$, the two clouds are considered to be the same at the two different time steps and the tracking continues to the next time step. These percentages are different than the settings described by Schröder et al. [2009]. Schröder et al. [2009] considered clouds with overlaps greater than $5 \%$, our study is more selective to be able to track smaller clouds. Moreover, Schröder et al. [2009] did not consider a threshold on the area, we decided to disregard cloud for which the area changes more than $50 \%$ between two time steps to avoid splitting or merging of clouds while we are tracking parameter temporal evolution.

(iii) Finally, we select clouds for which the temporal evolution follows some requirements: We focus on the cloud phase transition so we are interested by the moment when the cloud switches from liquid to ice. Several techniques can be used to define a cloud as liquid or ice. In the present study, we refer to the phase of the cloud coldest pixel: This method has already been used in previous studies [Schröder et al., 2009; Mecikalski et al., 2016] and we can therefore observe the beginning of the cloud glaciation. We require that each tracked cloud has its coldest pixel at least 30 minutes in the liquid and ice phase to be able to observe the phase transition. We define a reference time as the time for which the coldest pixel changes from liquid to ice, the process that all tracked clouds have in common, and is taken for synchronization [Mecikalski et al., 2016; Senf and Deneke, 2017].

The method is suited for isolated convective clouds which are surrounded by clear sky and the coldest pixel is able to represent cloud properties at the initiation of the cloud phase 
transition. Unfortunately, the method is not applicable for other cloud types (e.g., stratiform mixed-phase) and therefore they are not included in this study.

\subsection{Radiative Transfer Simulations}

Santa Barbara DISORT Atmospheric Radiative Transfer (SBDART) is a radiative transfer model which simulates cloud short-infrared reflectance measurements [Ricchiazzi et al., 1998]. The model has been designed for clear and cloudy atmospheric radiation studies and includes all important processes that occur in the visible and infrared wavelengths. SBDART is based on the discrete ordinate model of Stamnes et al. [1988]. The angular distribution of surface reflected radiation is assumed to be completely isotropic, irrespective of solar zenith angle (Lambertian reflection assumption). The model considers plane-parallel cloud structures and the cloud droplet size follows a gamma distribution with a fixed effective radius. To compute the scattering of cloud droplet, the Mie scattering code for spherical cloud droplets computes the extinction efficiency, the single scattering albedo, and the asymmetric factor.

SBDART has been used in previous studies [e.g., Gautier and Landsfeld, 1997; Smith and Toumi, 2008; Chiu et al., 2010] and it has been evaluated by Gautier and Landsfeld [1997] and in details by Ricchiazzi et al. [1998]. Cloud altitude, geometrical thickness, and water content can be varied but, for our study, an idealized one-layer cloud structure, vertically homogeneous, is assumed with only spherical particles for cloud droplets and ice crystals. We simulate radiances at the top of the atmosphere of (i) only liquid cloud, (ii) only ice clouds, and (iii) clouds containing cloud droplets and ice crystals representing the mixed-phase clouds.

The model considers six different atmospheric profiles to represent climatic conditions and five surface types. We use the standard mid-latitude atmospheric profile [McClatchey et al., 1972] and an ocean water surface to parametrize the spectral albedo of the surface [Tanré et al., 1990]. We compute radiance at 1.6 and $0.6 \mu \mathrm{m}$. The solar zenith angle is at $40^{\circ}$, cloud base and top are respectively located at $3 \mathrm{~km}$ and $4 \mathrm{~km}$ with a fixed effective radius fixed at $6 \mu \mathrm{m}$ and an ice crystal effective radius fixed at $28 \mu \mathrm{m}$. The cloud water path is set at $200 \mathrm{~g} \mathrm{~m}^{-2}$, and we vary the mass ice fraction from 0 to 1 . 


\section{Results}

\subsection{Observation results}

Between 2012 and 2015, from May to September, the cloud tracking algorithm is able to detect 230 convective clouds with an observed cloud phase transition of the coldest pixel from liquid to ice in the course of the tracked life time of the cloud. Figure 1-a shows the temporal evolution of $r_{e}$ for the 230 convective clouds considering the reference time of phase transition for synchronization between the clouds. We observe that at the phase transition the me$\operatorname{dian} r_{e}^{L i q}$ is slightly larger than the median $r_{e}^{I c e}$ : The median $r_{e}$ goes from $18.1 \mu \mathrm{m}$ at $t=-7.5 \mathrm{~min}$ to $17.9 \mu \mathrm{m}$ at $t=7.5 \mathrm{~min}$.

Figure 1-b shows that, for $48 \%$ of the observed clouds, the $r_{e}^{I c e}$ of the coldest pixel after the phase transition is smaller than $r_{e}^{L i q}$ of the coldest pixel before the phase transition which is unexpected: For a constant water content, at phase transition, ice crystal sizes are larger than the associated liquid droplets [Sassen and Dodd, 1988] due to the lower density of ice compared to liquid water and the difference is enhanced by the non-spherical crystalline growth. Indeed, liquid droplets are often of the order of $10 \mu \mathrm{m}$ and the size of ice particles can vary from few micrometers to more than $1 \mathrm{~mm}$ in diameter [Figure 1.24 in Lamb and Verlinde, 2011]. Also, the number concentration of liquid cloud droplets reduces drastically during glaciation (Wegener-Bergeron-Findeisen process). Even if the uncertainty in $r_{e}$ can be large, the signal we observe is larger than the associated uncertainties in most cases (see Figure S1, and Text S1 in the supporting information). The expected $r_{e}$ evolution with time $-r_{e}^{\text {Liq }}$ is smaller than $r_{e}^{I c e}$ — is shown in Figure 1-c and represent $51 \%$ of the tracked clouds, but they are not representative for the average cloud evolution.

As the coldest pixel can jump from one spatial region of the cloud to another, we did the same analysis with the $2 \%$ coldest pixels [Schröder et al., 2009] and the results are consistent and similar (see Figure S2 in the supporting information for more details).

Figure 2 shows two cases of cloud phase transitions for which $r_{e}^{I c e}$ is smaller than $r_{e}^{L i q}$ : on the $19^{\text {th }}$ of September 2012, a cloud above the Greek island Kithira with a diameter of about $30 \mathrm{~km}$, referred to as case 1 , and on the $12^{\text {th }}$ of August 2015 a typical continental summertime convective cloud with a diameter of about $100 \mathrm{~km}$, referred to as case 2 . Two time steps, fifteen minutes apart, are represented: before and after that the coldest pixel of the identified 
cloud switches from liquid to ice (for more examples of tracked clouds, you can refer to Figures S3 and S4 in the supporting information).

The two cases are showing different behaviors. In Figure 2-a for case 1, we observe that before the coldest pixel turns into ice, the tracked cloud is only liquid with a minimum temperature of $-1.15^{\circ} \mathrm{C}$ and a median temperature of $8.4^{\circ} \mathrm{C}$. When the coldest pixel turns into ice (Figure 2-b), the temperature of the coldest ice pixel is $-0.6^{\circ} \mathrm{C}$. We observe that the temperature of the coldest ice pixel is high: This pixel is probably not only ice but it is a mix of ice crystals and liquid droplets. From Figure 2-d for case 2, we observe that within the identified cloud, the coldest pixel is categorized as liquid but ice pixels are within the same temperature range. Before the phase transition (Figure 2-d), the minimum liquid-pixel temperature is $-18.15^{\circ} \mathrm{C}$, and the minimum ice pixel temperature is $-10.15^{\circ} \mathrm{C}$. After the phase transition (Figure 2-e), the minimum liquid-pixel temperature is $-17.15^{\circ} \mathrm{C}$, and the minimum ice pixel temperature is $-38.15^{\circ} \mathrm{C}$.

Figures 2-c and 2-f represent the evolution of $r_{e}$ in the coldest pixel of liquid and ice pixels, as well as the median $r_{e}$ of all liquid and ice pixels, respectively. The time for which the coldest-pixel phase changes from liquid to ice is represented by the vertical dashed gray lines in both figures. Considering Figure 2-c, the $r_{e}^{I c e}$ of the coldest pixel after the detected cloud phase transition has a smaller value than the $r_{e}^{L i q}$ of the coldest pixel before the phase transition: We observe a difference of $16.4 \mu \mathrm{m}$. Considering Figure 2-f, the median of $r_{e}^{I c e}$ is similar to the median of $r_{e}^{L i q}$ close to the phase transition: At the time step before the phase transition, the median $r_{e}^{I c e}$ is $14.9 \mu \mathrm{m}$ and the median $r_{e}^{L i q}$ is $13.3 \mu \mathrm{m}$. Considering the coldest pixel, $r_{e}^{I c e}$ after the transition $-11.7 \mu m-$ has a smaller value than $r_{e}^{L i q}$ before the transition $-14.4 \mu m$.

Figure 3-a shows the normalized distribution of ice pixel numbers before and after the phase transition considering all tracked clouds. We observe that $43 \%$ of clouds do not have ice pixel before the coldest pixel switches from liquid to ice. The other cases have at least one ice pixel before the coldest pixel switches from liquid to ice. Figure 3-b shows the normalized distribution of the difference in ice ratio (IR), i.e. the ice pixel number of the tracked cloud divided by the total pixel number within the cloud, after and before the phase transition for each tracked clouds. For $4 \%$ of the cases, there are more ice pixels before the phase transition than after. Otherwise, we observe that the maximum of the distribution of the difference in ice ratio in Fig. $3 b$ is greater than zero which is in line with our expectations: There are 
more ice pixels after the phase transition than before. Some tracked clouds present a large number of ice pixels before the phase transition, as shown in Figure 3-a by the light blue line, but regarding the ice ratio variation, the number of ice pixels before the phase transition remains smaller than after the phase transition for $96 \%$ of the tracked clouds.

On Figures 2-c and 2-f, the errorbars associated with the coldest-pixel effective radius are the uncertainty given by the retrieval. We note that in both cases, the decrease in $r_{e}$ is larger than the uncertainty. Therefore, we cannot attribute the observed decrease in $r_{e}$ to the measurement uncertainty. The decrease of the ice crystal radii could also be explained by the shattering of large ice crystals. But, similarly, the signal of small ice crystals happens only at the phase transition and not when the cloud is in the ice phase for which ice crystal radii are up to $25 \mu \mathrm{m}$. Therefore, secondary ice production alone cannot explain the observed variation. Precipitation of large ice crystals could explain the decrease of effective radius at the phase transition observed in Figure 1-a, but this decrease is not observed for liquid cloud droplets: In Figure 1-b, cloud droplet effective radii are around $24 \mu \mathrm{m}$ and $r_{e}^{I c e}$ is $18 \mu \mathrm{m}$. Moreover, the large ice crystals after the phase transition of the order of $24 \mu \mathrm{m}$ at cloud top in Figure 1-c are not precipitating. Precipitation of large ice crystals cannot explain the decrease in $r_{e}^{I c e}$.

We explore the reasons for $r_{e}^{I c e}<r_{e}^{L i q}$ at the phase transition by analyzing the retrieval of $r_{e}$.

\subsection{Simulated results}

As mentioned in Section 2, CLAAS-2 $r_{e}$ and $\tau$ are retrieved from the 0.6 and $1.6 \mu m$ channels [Benas et al., 2017]. The Nakajima \& King diagram [Nakajima and King, 1990] demonstrates the sensitivity of the channel reflectances with respect to $\tau$ and $r_{e}$. An example is shown in Figure 4 considering a solar zenithal angle of $40^{\circ}$, a satellite zenithal angle of $30^{\circ}$, and a satellite azimuthal angle of $140^{\circ}$ for liquid and ice cloud top. We observe that the radiance at $0.6 \mu \mathrm{m}$ is sensitive to variations in $\tau$ whereas the sensitivity of the radiance at $1.6 \mu \mathrm{m}$ is marginal for optically thick cloud; for optically thin clouds $-\tau<10-$ the 1.6 radiance becomes also sensitive to $\tau$. The opposite is true for variations in $r_{e}$ : The radiance at $1.6 \mu \mathrm{m}$ is sensitive to variations in $r_{e}$ whereas the radiance at $0.6 \mu \mathrm{m}$ is not. The overlap between the ice and liquid diagrams implies that two $r_{e}$ can be retrieved for the same measured radiances: The radiances of $r_{e}^{L i q}$ retrievals ranging from 12 to $34 \mu \mathrm{m}$ overlap with the radiances of $r_{e}^{I c e}$ retrievals ranging from 5 to $14 \mu \mathrm{m}$. For example, if the measured radiances at 0.6 and $1.6 \mu \mathrm{m}$ are respec- 
tively 269 and $23 \mathrm{~W} \mathrm{~m}^{-2} \mu m \mathrm{str}^{-1}$, the retrievals can be $r_{e}^{L i q}=17 \mu m$ with $\tau=32$ considering a liquid cloud top or $r_{e}^{I c e}=7 \mu m$ with $\tau=32$ considering an ice cloud top. The cloud phase is determined by a decision tree based on cloud optical properties. Therefore, mixed-phase pixel can be labeled as ice or liquid. Algorithms based on passive instruments need to have a reliable information on the cloud phase to retrieve $r_{e}$, but mixed-phase clouds are not considered.

Using SBDART, we simulate the radiances of an uniform mixed-phase cloud for ice mass fraction $\left(\chi_{\text {Ice }}\right)$ ranging from zero to one, shown in Figure 4 as a black line with colored circles. The water path is kept constant at $200 \mathrm{~g} \mathrm{~m}^{-2}, r_{e}^{L i q}$ and $r_{e}^{I c e}$ are respectively set at 6 and $28 \mu \mathrm{m} . \chi_{\text {Ice }}$ values are based on the ratio of the weight of ice crystals by the sum of the weights of the liquid droplets and ice crystals. We observe that when $\chi_{\text {Ice }}=0$ and $\chi_{\text {Ice }}=1$, the simulated $r_{e}$ is respectively equal to $6 \mu m$ and $28 \mu m$, consistent with our initial settings. Between these two $\chi_{\text {Ice }}$ extrema, both radiances at 0.6 and $1.6 \mu \mathrm{m}$ decrease when $\chi_{\text {Ice }}$ increases from zero to one. For $\chi_{\text {Ice }}$ ranging from 0.4 to 0.8 , the simulated radiances are in the overlap region of liquid and ice phase detection. A data set using a passive space-based instrument, such as CLAAS-2 with SEVIRI, calculates $r_{e}$ based on a binary phase determination prior to the $r_{e}$ calculation. In such approach, mixed-phase clouds are not well represented.

Figure 5 shows the variations of the simulated $r_{e}$ considering $\chi_{\text {Ice }}$ from zero to one for liquid and ice clouds on the Nakajima \& King diagram. If the cloud top is considered liquid, $r_{e}^{L i q}$ is increased by $1 \mu \mathrm{m}$ between $\chi_{\text {Ice }}=0$ and $\chi_{\text {Ice }}=0.1$. If the cloud top is considered ice, $r_{e}^{I c e}$ is decreased by $11 \mu m$ between $\chi_{I c e}=1$ and $\chi_{I c e}=0.9$. An algorithm with a binary cloud-phase information can detect the phase transition at the pixel level when $\chi_{\text {Ice }}$ is equal to specific value, for example 0.5 . In this case, the retrieved $r_{e}^{L i q}$ before the phase transition and the retrieved $r_{e}^{I c e}$ after the phase transition would drop from 14 to $6 \mu m$ whereas $r_{e}^{L i q}$ and $r_{e}^{I c e}$ are respectively set at 6 and $28 \mu m$. For an ice fraction different than $1, r_{e}^{I c e}$ is artificially decreased and for an ice fraction different than $0, r_{e}^{L i q}$ is artificially increased.

Indeed, when liquid spherical droplets coexist with ice particles, we anticipate a higher absorption by ice particles in the SWIR band [Riedi et al., 2010; Platnick et al., 2014]. When in a mixed phase cloud liquid cloud droplets coexist with ice particles the reflectance in the SWIR will be lower than for a pure liquid cloud and higher than a pure ice clouds. Once the cloud phase is determined, the retrieved effective radius will increase with decreasing SWIR reflectance as can be seen in the Nakajima \& King plot in Figure 4. As in (common) retrieval 
algorithms the phase is just a binary classification, systematic errors are made when cloud properties are retrieved for clouds which are of mixed-phase in nature. Assuming a cloud that has an increasing portion of ice particles but is still believed to be liquid, the retrieval will result in increasing liquid effective radii just by in the increase of ice particles in the cloud, even though the particle sizes are not changing. Is the cloud assigned to be ice at some point, the retrieved ice effective radius will be biased low as long as long as there is still liquid particles in the cloud. This low bias will reduced with increasing ice portion (thus with decreasing liquid portion) in the cloud.

\section{Discussions}

Figure 6 shows the mean temporal evolution of cloud top temperature considering all tracked clouds (Figure 6-a), $r_{e}^{I c e} \leqslant r_{e}^{L i q}$ (Figure 6-b), and $r_{e}^{I c e}>r_{e}^{\text {Liq }}$ (Figure 6-c). We observe that for $r_{e}^{I c e} \leqslant r_{e}^{L i q}$, the difference in temperature between the last liquid and the first ice is smaller than for $r_{e}^{I c e}>r_{e}^{L i q}$ : When $r_{e}^{I c e} \leqslant r_{e}^{L i q}, \Delta T$ is $13^{\circ} \mathrm{C}$, whereas when $r_{e}^{I c e}>r_{e}^{L i q}$, $\Delta T$ is $22^{\circ} \mathrm{C}$, with $\Delta T=T_{\text {Last Liquid }}-T_{\text {First Ice }}$. We find a slower ascension of cloud top when $r_{e}^{I c e} \leqslant r_{e}^{L i q}$ which corresponds to the clouds labeled as mixed-phase. This result suggests that the cooling is faster for non-mixed-phase clouds and we cannot detect mixed-phase pixels at 15 minute time intervals.

Considering Figures 1-c, 2-c, 2-f, and 5, we observe that, at the phase transition, the retrieved $r_{e}^{I c e}$ can be smaller than $r_{e}^{L i q}$, which is physically unexpected. During the tracking of a cloud, if $r_{e}$ decreases when the phase change from liquid to ice according to a binary-phase retrieval, then the cloud is most probably in the mixed phase. Precautions need to be taken in order to study the evolution of $r_{e}$ because the binary phase information does not allow a full description of cloud radiative properties. Our results do not imply that the cases presented in Figure 1-c for which $r_{e}^{L i q}$ is smaller than $r_{e}^{I c e}$ are never in a mixed-phase state, but rather that the coldest pixel moved from approximately 100\% liquid to approximately $100 \%$ ice within the 15 minutes between two measurements, and for these cases the algorithm do not detect mixed-phase pixels. $r_{e}^{I c e}$ smaller than $r_{e}^{L i q}$ can serve as a proxy to detect the presence of mixedphase cloud during cloud tracking from a passive instrument.

Cloud radiative properties cannot be entirely described by only liquid and ice phase. Therefore, it leads to biases when analyzing the evolution of cloud optical properties. Therefore, the temporal evolution of $r_{e}$ at the phase transition needs to be analyzed carefully. Our study fo- 
cuses on the phase transition, but any retrieval of mixed-phase cloud pixels will exhibit the same problem: $r_{e}^{I c e}$ is artificially small, and $r_{e}^{L i q}$ is artificially large. Moreover, the tracking algorithm is designed for isolated convective clouds, but many other types of clouds experience a mixed-phase state [e.g., arctic stratus, Mioche et al., 2015] with different spatial configurations of ice and water [Sun and Shine, 1994]: uniform, stratified, and adjacent.

Table 1 shows the variations in $r_{e}$ before, during, and after the phase transition for the three regimes from Figure 1. We notice that the increase in $r_{e}^{L i q}$ before the phase transition is larger in the case of detected mixed-phase clouds (i.e. $r_{e}^{\text {Liq }} \geqslant r_{e}^{I c e}$ ) than in the other cases: The increase in $r_{e}^{L i q}$ between the relative times -22.5 and -7.5 minutes is equal to $4.6 \mu m$ when $r_{e}^{L i q} \geqslant r_{e}^{I c e}$ and is equal to $0.32 \mu m$ when $r_{e}^{L i q}<r_{e}^{I c e}$. The presence of ice within the pixel can increase $r_{e}^{L i q}$ before the phase transition and, therefore, the variations in $r_{e}^{L i q}$ is increased.

Similarly, we notice that the increase in $r_{e}^{I c e}$ after the phase transition is larger in the case of detected mixed-phase clouds than in the other cases: $r_{e}^{I c e}$ increases by $2.8 \mu m$ between the relative times 7.5 and 22.5 minutes when $r_{e}^{L i q} \geqslant r_{e}^{I c e}$ and decreases by $0.6 \mu m$ when $r_{e}^{L i q}<$ $r_{e}^{I c e}$. The presence of liquid droplet within the ice pixel after the phase transition can decrease $r_{e}^{I c e}$ and increase the variation in $r_{e}^{I c e}$ after the phase transition.

The method described in the article allows to detect individual mixed-phase pixels. Unfortunately, we are unable to asses if the detected pixel is in the mixed phase before or after the phase transition and if the mixed phase state concerns only the coldest pixel or the full clouds. Nevertheless, the intermediate mixed-phase state of a cloud cell is inferred from analyzing the temporal evolution of pixel-level information evaluating all pixels of that cloud cell. Thus, we use pixel-based information to assign a cloud cell to be in a mixed-phase state, even if only parts of the cloud cell (thus the coldest pixels of that cloud cell) contributed to that information. With that information we can highlight that mixed-phase clouds exist and it is actually possible to show this by the temporal evolution of the pixel-level effective radius even though the cloud phase information is only binary (liquid or ice) in each individual pixel.

\section{Conclusion}

From CLAAS-2, based on the geostationary space-based instrument SEVIRI, we are able to track 230 clouds over Europe between May and September from 2012 to 2015. The temporal evolution of the median effective radius shows that at the phase transition ice crystals are smaller than cloud droplets which is unexpected for $48 \%$ of the tracked clouds. As an ex- 
ample, we described two cases for which $r_{e}^{I c e}$ is unexpectedly smaller than $r_{e}^{L i q}$ at the phase transition. We are able to reproduce this difference by simulating radiative properties of a uniform mixed-phase cloud for which $r_{e}$ is determined by a binary phase detection. The binary phase detection do not allow to retrieve an $r_{e}$ for mixed-phase pixels, and retrieve artificially small ice crystals and artificially large liquid cloud droplets at the phase transition. The observed signal, presented here, can serve to detect mixed-phase clouds from passive-space-based measurements on a cloud tracking algorithm.

In Figures 2-d and 2-e, we observe that ice and liquid pixels coexist before and after the phase transition. We can use our dataset to study the evolution of liquid-ice partitioning and link it to the temperature of transition. We based our study on the coldest pixel to observe the microphysical properties on the pixel level, but an extension of the study could analyze the fraction of ice pixels within the cloud object, to retrieve information on the speed of glaciation of clouds.

Several algorithms track cloud entities and cloud microphysical properties with geostationary satellites [Guilbert and Lin, 2007; Zinner et al., 2008; Berendes et al., 2008; Bennartz and Schroeder, 2012; Senf et al., 2015; Bley et al., 2016; Senf and Deneke, 2017; Zhu et al., 2017; Patou et al., 2018]. The information on $r_{e}$ could be used to detect mixed-phase clouds. A large dataset of these clouds would help to better understand their formation and evolution [Klein et al., 2009; Cesana et al., 2012; Mioche et al., 2015]. Current passive sensor algorithms do not represent well mixed-phase clouds, we could consider different cloud thermodynamic phases [Sun and Shine, 1994; Noh and Miller, 2018] to study optical properties of mixed-phase clouds. Also it would be beneficial to develop a Nakajima \& King diagram considering pixels for different mixed-phase cloud categories [Sun and Shine, 1994; Noh and Miller, 2018] to observe the variation of $r_{e}$ at the phase transition. We compared passive satellite observations with a numerical model output but a comparison of our results with active satellite observations, raDAR/liDAR (DARDAR) algorithm for example [Delanoë and Hogan, 2010] could validate our results and provide more information on the type of mixed-phase clouds we are observing. The present study can help future research to select mixed-phase pixels within mixed-phase clouds to analyze the optical, microphysical, and dynamical properties of these specific pixels.

\section{Acknowledgments}

The CLAAS-2 dataset can be found on the following link: https://doi.org/10.5676/EUM_SAF_CM/CLAAS/V002. The SBDART model is available through the following link: https://github.com/paulricchiazzi/SBDART 
The authors acknowledge support by the state of Baden-Württemberg through bwHPC. This project has received funding from the European Research Council (ERC) under the European Union's Horizon 2020 research and innovation programme (grant agreement $\mathrm{n}^{\circ}$ 714062).

\section{References}

Benas, N., S. Finkensieper, M. Stengel, G.-J. van Zadelhoff, T. Hanschmann, R. Hollmann, and J. F. Meirink (2017), The MSG-SEVIRI-based cloud property data record CLAAS-2, Earth System Science Data, 9(2), 415-434, doi:10.5194/essd-9-415-2017.

Bennartz, R., and M. Schroeder (2012), Convective Activity over Africa and the Tropical Atlantic Inferred from 20 Years of Geostationary Meteosat Infrared Observations, Journal of Climate, 25(1), 156-169, doi:10.1175/2011JCLI3984.1.

Berendes, T. A., J. R. Mecikalski, W. M. MacKenzie, K. M. Bedka, and U. S. Nair (2008), Convective cloud identification and classification in daytime satellite imagery using standard deviation limited adaptive clustering, Journal of Geophysical Research, 113(D20), D20,207, doi:10.1029/2008JD010287.

Bley, S., H. Deneke, and F. Senf (2016), Meteosat-Based Characterization of the Spatiotemporal Evolution of Warm Convective Cloud Fields over Central Europe, Journal of Applied Meteorology and Climatology, 55(10), 2181-2195, doi:10.1175/JAMC-D-150335.1.

Boers, R., and R. M. Mitchell (1994), Absorption feedback in stratocumulus clouds Influence on cloud top albedo, Tellus A, 46(3), 229-241, doi:10.1034/j.16000870.1994.00001.x.

Bréon, F.-M., and S. Colzy (1999), Cloud Detection from the Spaceborne POLDER Instrument and Validation against Surface Synoptic Observations, Journal of Applied Meteorology, 38(6), 777-785, doi:10.1175/1520-0450(1999)038<0777:CDFTSP>2.0.CO;2.

Carro-Calvo, L., C. Hoose, M. Stengel, and S. Salcedo-Sanz (2016), Cloud glaciation temperature estimation from passive remote sensing data with evolutionary computing, Journal of Geophysical Research: Atmospheres, 121(22), 13,591-13,608, doi: 10.1002/2016JD025552.

Cesana, G., J. E. Kay, H. Chepfer, J. M. English, and G. de Boer (2012), Ubiquitous low-level liquid-containing Arctic clouds: New observations and climate model constraints from CALIPSO-GOCCP, Geophysical Research Letters, 39(20), doi: 10.1029/2012GL053385. 
Chiu, J. C., A. Marshak, Y. Knyazikhin, and W. J. Wiscombe (2010), Spectrally-invariant behavior of zenith radiance around cloud edges simulated by radiative transfer, Atmospheric Chemistry and Physics, 10(22), 11,295-11,303, doi:10.5194/acp-10-11295-2010.

Cober, S. G., G. a. Isaac, A. V. Korolev, and J. W. Strapp (2001), Assessing Cloud-Phase Conditions, Journal of Applied Meteorology, 40(11), 1967-1983, doi:10.1175/15200450(2001)040<1967:ACPC>2.0.CO;2.

Coopman, Q., J. Riedi, D. P. Finch, and T. J. Garrett (2018), Evidence for changes in arctic cloud phase due to long-range pollution transport, Geophysical Research Letters, pp. 1-19, doi:10.1029/2018GL079873.

Dee, D. P., S. M. Uppala, a. J. Simmons, P. Berrisford, P. Poli, S. Kobayashi, U. Andrae, M. a. Balmaseda, G. Balsamo, P. Bauer, P. Bechtold, a. C. M. Beljaars, L. van de Berg, J. Bidlot, N. Bormann, C. Delsol, R. Dragani, M. Fuentes, a. J. Geer, L. Haimberger, S. B. Healy, H. Hersbach, E. V. Hólm, L. Isaksen, P. Kållberg, M. Köhler, M. Matricardi, A. P. McNally, B. M. Monge-Sanz, J.-J. Morcrette, B.-K. Park, C. Peubey, P. de Rosnay, C. Tavolato, J.-N. Thépaut, and F. Vitart (2011), The ERA-Interim reanalysis: configuration and performance of the data assimilation system, Quarterly Journal of the Royal Meteorological Society, 137(656), 553-597, doi:10.1002/qj.828.

Delanoë, J., and R. J. Hogan (2010), Combined CloudSat-CALIPSO-MODIS retrievals of the properties of ice clouds, Journal of Geophysical Research, 115(4), D00H29, doi:10.1029/2009JD012346.

Derrien, M. (2013), Algorithm Theoretical Basis Document for Cloud Products (CMaPGE01 v3.2, CT-PGE02 v2.2 \& CTTH-PGE03 v2.2), Tech. Rep. 3.2.1, EUMETSAT Satellite Application Facility on Nowcasting and Short range Forecasting.

Derrien, M., and H. Le Gléau (2005), MSG/SEVIRI cloud mask and type from SAFNWC, International Journal of Remote Sensing, 26(21), 4707-4732, doi: $10.1080 / 01431160500166128$.

Fleishauer, R. P., V. E. Larson, and T. H. Vonder Haar (2002), Observed Microphysical Structure of Midlevel, Mixed-Phase Clouds, Journal of the Atmospheric Sciences, 59(11), 1779-1804, doi:10.1175/1520-0469(2002)059<1779:OMSOMM>2.0.CO;2.

Gautier, C., and M. Landsfeld (1997), Surface Solar Radiation Flux and Cloud Radiative Forcing for the Atmospheric Radiation Measurement (ARM) Southern Great Plains (SGP): A Satellite, Surface Observations, and Radiative Transfer Model Study, Journal of the Atmospheric Sciences, 54(10), 1289-1307, doi:10.1175/1520- 
0469(1997)054<1289:SSRFAC>2.0.CO;2.

Guilbert, E., and H. Lin (2007), A New Model for Cloud Tracking and Analysis on Satellite Images, GeoInformatica, 11(3), 287-309, doi:10.1007/s10707-006-0008-6.

Hansen, J., M. Sato, and R. Ruedy (1997), Radiative forcing and climate response, Journal of Geophysical Research: Atmospheres, 102(D6), 6831-6864, doi: 10.1029/96JD03436.

Huang, D., K. Johnson, Y. Liu, and W. Wiscombe (2009), High resolution retrieval of liquid water vertical distributions using collocated Ka-band and W-band cloud radars, Geophysical Research Letters, 36(24), L24,807, doi:10.1029/2009GL041364.

Klein, S. A., R. B. McCoy, H. Morrison, A. S. Ackerman, A. Avramov, G. de Boer, M. Chen, J. N. S. Cole, A. D. Del Genio, M. Falk, M. J. Foster, A. Fridlind, J.-C. Golaz, T. Hashino, J. Y. Harrington, C. Hoose, M. F. Khairoutdinov, V. E. Larson, X. Liu, Y. Luo, G. M. McFarquhar, S. Menon, R. A. J. Neggers, S. Park, M. R. Poellot, J. M. Schmidt, I. Sednev, B. J. Shipway, M. D. Shupe, D. A. Spangenberg, Y. C. Sud, D. D. Turner, D. E. Veron, K. von Salzen, G. K. Walker, Z. Wang, A. B. Wolf, S. Xie, K.-M. Xu, F. Yang, and G. Zhang (2009), Intercomparison of model simulations of mixed-phase clouds observed during the ARM Mixed-Phase Arctic Cloud Experiment. I: single-layer cloud, Quarterly Journal of the Royal Meteorological Society, 135(641), 979-1002, doi:10.1002/qj.416.

Kopp, T. J., W. Thomas, A. K. Heidinger, D. Botambekov, R. A. Frey, K. D. Hutchison, B. D. Iisager, K. Brueske, and B. Reed (2014), The VIIRS Cloud Mask: Progress in the first year of S-NPP toward a common cloud detection scheme, Journal of Geophysical Research: Atmospheres, 119(5), 2441-2456, doi:10.1002/2013JD020458.

Korolev, A., G. McFarquhar, P. R. Field, C. Franklin, P. Lawson, Z. Wang, E. Williams, S. J. Abel, D. Axisa, S. Borrmann, J. Crosier, J. Fugal, M. Krämer, U. Lohmann, O. Schlenczek, M. Schnaiter, and M. Wendisch (2017), Mixed-Phase Clouds: Progress and Challenges, Meteorological Monographs, 58, 5.1-5.50, doi: 10.1175/AMSMONOGRAPHS-D-17-0001.1.

Lamb, D., and J. Verlinde (2011), Physics and chemistry of clouds, Cambridge University Press.

Larson, V. E., A. J. Smith, M. J. Falk, K. E. Kotenberg, and J.-C. Golaz (2006), What determines altocumulus dissipation time?, Journal of Geophysical Research, 111(D19), D19,207, doi:10.1029/2005JD007002. 
Matricardi, M., F. Chevallier, G. Kelly, and J.-N. Thépaut (2004), An improved general fast radiative transfer model for the assimilation of radiance observations, Quarterly Journal of the Royal Meteorological Society, 130(596), 153-173, doi:10.1256/qj.02.181.

McClatchey, R. A., R. W. Fenn, J. E. A. Selby, F. E. Volz, and J. S. Garing (1972), Optical Properties of the Atmosphere, Tech. rep., AIR FORCE CAMBRIDGE RESEARCH LABS HANSCOM AFB MA, Bedfor.

McCoy, D. T., I. Tan, D. L. Hartmann, M. D. Zelinka, and T. Storelvmo (2016), On the relationships among cloud cover, mixed-phase partitioning, and planetary albedo in GCMs, Journal of Advances in Modeling Earth Systems, 8(2), 650-668, doi: 10.1002/2015MS000589.

Mecikalski, J. R., C. P. Jewett, J. M. Apke, and L. D. Carey (2016), Analysis of Cumulus Cloud Updrafts as Observed with 1-Min Resolution Super Rapid Scan GOES Imagery, Monthly Weather Review, 144(2), 811-830, doi:10.1175/MWR-D-14-00399.1.

Meirink, J. F., and G. J. van Zadelhoff (2016), Algorithm Theoretical Basis Document, SEVIRI Cloud Physical Products, CLAAS Edition 2, Tech. Rep. 2.2, EUMETSAT Satellite Application Facility on Climate Monitoring, doi: 10.5676/EUM_SAF_CM/CLAAS/V002.

Meirink, J. F., R. A. Roebeling, and P. Stammes (2013), Inter-calibration of polar imager solar channels using SEVIRI, Atmospheric Measurement Techniques, 6(9), 2495-2508, doi:10.5194/amt-6-2495-2013.

Menzel, W. P., W. L. Smith, and T. R. Stewart (1983), Improved Cloud Motion Wind Vector and Altitude Assignment Using VAS, Journal of Climate and Applied Meteorology, 22(3), 377-384, doi:10.1175/1520-0450(1983)022<0377:ICMWVA>2.0.CO;2.

Mioche, G., O. Jourdan, M. Ceccaldi, and J. Delanoë (2015), Variability of mixed-phase clouds in the Arctic with a focus on the Svalbard region: a study based on spaceborne active remote sensing, Atmospheric Chemistry and Physics, 15(5), 2445-2461, doi:10.5194/acp-15-2445-2015.

Mouri, K., T. Izumi, H. Suzue, and R. Yoshida (2016), Algorithm Theoretical Basis Document of cloud type/phase product., Meteorological Satellite Center Technical Note, (61), $19-31$.

Nakajima, T., and M. D. King (1990), Determination of the Optical Thickness and Effective Particle Radius of Clouds from Reflected Solar Radiation Measurements. Part I: Theory, Journal of the Atmospheric Sciences, 47(15), 1878-1893, doi:10.1175/1520- 
0469(1990)047<1878:DOTOTA>2.0.CO;2.

Noh, Y.-J., and S. D. Miller (2018), Detection of Mixed-Phase Clouds From Shortwave and Thermal Infrared Satellite Observations, in Mixed-Phase Clouds, edited by C. Andronache, chap. Noh2018, pp. 43-67, Elsevier, doi:10.1016/B978-0-12-810549-8.000039.

Noh, Y.-J., C. J. Seaman, T. H. Vonder Haar, D. R. Hudak, and P. Rodriguez (2011), Comparisons and analyses of aircraft and satellite observations for wintertime mixed-phase clouds, Journal of Geophysical Research, 116(D18), D18,207, doi: 10.1029/2010JD015420.

Noh, Y.-J., C. J. Seaman, T. H. Vonder Haar, and G. Liu (2013), In Situ Aircraft Measurements of the Vertical Distribution of Liquid and Ice Water Content in Midlatitude Mixed-Phase Clouds, Journal of Applied Meteorology and Climatology, 52(1), 269-279, doi:10.1175/JAMC-D-11-0202.1.

Patou, M., J. Vidot, J. Riédi, G. Penide, and T. J. Garrett (2018), Prediction of the onset of heavy rain using SEVIRI cloud observations, Journal of Applied Meteorology and Climatology, pp. JAMC-D-17-0352.1, doi:10.1175/JAMC-D-17-0352.1.

Pavolonis, M. J., A. K. Heidinger, and T. Uttal (2005), Daytime Global Cloud Typing from AVHRR and VIIRS: Algorithm Description, Validation, and Comparisons, Journal of Applied Meteorology, 44(6), 804-826, doi:10.1175/JAM2236.1.

Platnick, S., M. King, S. Ackerman, W. Menzel, B. Baum, J. Riedi, and R. Frey (2003), The MODIS cloud products: algorithms and examples from terra, IEEE Transactions on Geoscience and Remote Sensing, 41(2), 459-473, doi:10.1109/TGRS.2002.808301.

Platnick, S., M. D. King, K. G. Meyer, G. Wind, N. Amarasinghe, B. Marchant, G. T. Arnold, Z. Zhang, P. A. Hubanks, B. Ridgway, and J. Riedi (2014), MODIS Cloud Optical Properties: User Guide for the Collection 6 Level-2 MOD06/MYD06 Product and Associated Level-3 Datasets, Tech. rep.

Rangno, A. L., and P. V. Hobbs (2001), Ice particles in stratiform clouds in the Arctic and possible mechanisms for the production of high ice concentrations, Journal of Geophysical Research: Atmospheres, 106(D14), 15,065-15,075, doi:10.1029/2000JD900286.

Rauber, R. M., and A. Tokay (1991), An Explanation for the Existence of Supercooled Water at the Top of Cold Clouds, Journal of the Atmospheric Sciences, 48(8), 10051023, doi:10.1175/1520-0469(1991)048<1005:AEFTEO>2.0.CO;2. 
Ricchiazzi, P., S. Yang, C. Gautier, and D. Sowle (1998), SBDART: A Research and Teaching Software Tool for Plane-Parallel Radiative Transfer in the Earth's Atmosphere, Bulletin of the American Meteorological Society, 79(10), 2101-2114, doi:10.1175/15200477(1998)079<2101:SARATS>2.0.CO;2.

Riedi, J., B. Marchant, S. Platnick, B. A. Baum, F. Thieuleux, C. Oudard, F. Parol, J.-M. Nicolas, and P. Dubuisson (2010), Cloud thermodynamic phase inferred from merged POLDER and MODIS data, Atmospheric Chemistry and Physics, 10(23), 11,85111,865, doi:10.5194/acp-10-11851-2010.

Roebeling, R. A., A. J. Feijt, and P. Stammes (2006), Cloud property retrievals for climate monitoring: Implications of differences between Spinning Enhanced Visible and Infrared Imager (SEVIRI) on METEOSAT-8 and Advanced Very High Resolution Radiometer (AVHRR) on NOAA-17, Journal of Geophysical Research, 111(D20), D20,210, doi:10.1029/2005JD006990.

Rosenfeld, D., and I. M. Lensky (1998), SatelliteBased Insights into Precipitation Formation Processes in Continental and Maritime Convective Clouds, Bulletin of the American Meteorological Society, 79(11), 2457-2476, doi:10.1175/15200477(1998)079<2457:SBIIPF>2.0.CO;2.

Rosenfeld, D., X. Yu, G. Liu, X. Xu, Y. Zhu, Z. Yue, J. Dai, Z. Dong, Y. Dong, and Y. Peng (2011), Glaciation temperatures of convective clouds ingesting desert dust, air pollution and smoke from forest fires, Geophysical Research Letters, 38(21), L21,804, doi:10.1029/2011GL049423.

Sassen, K., and G. C. Dodd (1988), Homogeneous Nucleation Rate for Highly Supercooled Cirrus Cloud Droplets, Journal of the Atmospheric Sciences, 45(8), 1357-1369, doi:10.1175/1520-0469(1988)045<1357:HNRFHS>2.0.CO;2 .

Saunders, R., M. Matricardi, and P. Brunel (1999), An improved fast radiative transfer model for assimilation of satellite radiance observations, Quarterly Journal of the Royal Meteorological Society, 125(556), 1407-1425, doi:10.1002/qj.1999.49712555615.

Schmetz, J., K. Holmlund, J. Hoffman, B. Strauss, B. Mason, V. Gaertner, A. Koch, and L. Van De Berg (1993), Operational Cloud-Motion Winds from Meteosat Infrared Images, Journal of Applied Meteorology, 32(7), 1206-1225, doi:10.1175/15200450(1993)032<1206:OCMWFM>2.0.CO;2.

Schmetz, J., P. Pili, S. Tjemkes, D. Just, J. Kerkmann, S. Rota, and A. Ratier (2002), An Introduction to Meteosat Second Generation (MSG), Bulletin 
of the American Meteorological Society, 83(7), 977-992, doi:10.1175/15200477(2002)083<0977:AITMSG>2.3.CO;2.

Schmit, T. J., P. Griffith, M. M. Gunshor, J. M. Daniels, S. J. Goodman, and W. J. Lebair (2017), A Closer Look at the ABI on the GOES-R Series, Bulletin of the American Meteorological Society, 98(4), 681-698, doi:10.1175/BAMS-D-15-00230.1.

Schröder, M., M. König, and J. Schmetz (2009), Deep convection observed by the Spinning Enhanced Visible and Infrared Imager on board Meteosat 8: Spatial distribution and temporal evolution over Africa in summer and winter 2006, Journal of Geophysical Research, 114(D5), D05,109, doi:10.1029/2008JD010653.

Senf, F., and H. Deneke (2017), Satellite-Based Characterization of Convective Growth and Glaciation and Its Relationship to Precipitation Formation over Central Europe, Journal of Applied Meteorology and Climatology, 56(7), 1827-1845, doi:10.1175/JAMCD-16-0293.1.

Senf, F., F. Dietzsch, A. Hünerbein, and H. Deneke (2015), Characterization of Initiation and Growth of Selected Severe Convective Storms over Central Europe with MSG-SEVIRI, Journal of Applied Meteorology and Climatology, 54(1), 207-224, doi: 10.1175/JAMC-D-14-0144.1.

Shupe, M. D., J. S. Daniel, G. de Boer, E. W. Eloranta, P. Kollias, C. N. Long, E. P. Luke, D. D. Turner, and J. Verlinde (2008), A Focus On Mixed-Phase Clouds, Bulletin of the American Meteorological Society, 89(10), 1549-1562, doi: 10.1175/2008BAMS2378.1.

Smith, S., and R. Toumi (2008), Measuring Cloud Cover and Brightness Temperature with a Ground-Based Thermal Infrared Camera, Journal of Applied Meteorology and Climatology, 47(2), 683-693, doi:10.1175/2007JAMC1615.1.

Stammes, P. (2001), Spectral radiance modelling in the UV-Visible range, in IRS 2000: Current Problems in Atmospheric Radiation, edited by W. L. Smith and Y. M. Timofeye, pp. 385-388, A. Deepak Publ., Hampton, VA.

Stamnes, K., S.-C. Tsay, W. Wiscombe, and K. Jayaweera (1988), Numerically stable algorithm for discrete-ordinate-method radiative transfer in multiple scattering and emitting layered media, Applied Optics, 27(12), 2502, doi:10.1364/AO.27.002502.

Stengel, M. S., A. K. Kniffka, J. F. M. Meirink, M. L. Lockhoff, J. T. Tan, and R. H. Hollmann (2014), CLAAS: the CM SAF cloud property data set using SEVIRI, Atmospheric Chemistry and Physics, 14(8), 4297-4311, doi:10.5194/acp-14-4297-2014. 
Sun, Z., and K. P. Shine (1994), Studies of the radiative properties of ice and mixedphase clouds, Quarterly Journal of the Royal Meteorological Society, 120(515), 111-137, doi:10.1002/qj.49712051508

Tanré, D., C. Deroo, P. Duhaut, M. Herman, J. J. Morcrette, J. Perbos, and P.-Y. Deschamps (1990), Technical note Description of a computer code to simulate the satellite signal in the solar spectrum: the 5S code, International Journal of Remote Sensing, 11(4), 659-668, doi:10.1080/01431169008955048.

Winker, D. M., M. a. Vaughan, A. Omar, Y. Hu, K. a. Powell, Z. Liu, W. H. Hunt, and S. a. Young (2009), Overview of the CALIPSO Mission and CALIOP Data Processing Algorithms, Journal of Atmospheric and Oceanic Technology, 26(11), 2310-2323, doi:10.1175/2009JTECHA1281.1

Yuan, T., J. V. Martins, Z. Li, and L. A. Remer (2010), Estimating glaciation temperature of deep convective clouds with remote sensing data, Geophysical Research Letters, 37(8), 1-5, doi:10.1029/2010GL042753.

Zamora, L. M., R. A. Kahn, K. B. Huebert, A. Stohl, and S. Eckhardt (2018), A satellitebased estimate of aerosol-cloud microphysical effects over the Arctic Ocean, Atmospheric Chemistry and Physics Discussions, (May), 1-22, doi:10.5194/acp-2018-514.

Zhang, D., Z. Wang, and D. Liu (2010), A global view of midlevel liquid-layer topped stratiform cloud distribution and phase partition from CALIPSO and CloudSat measurements, Journal of Geophysical Research, 115(4), D00H13, doi:10.1029/2009JD012143.

Zhu, R., E. Guilbert, and M. S. Wong (2017), Object-oriented tracking of the dynamic behavior of urban heat islands, International Journal of Geographical Information Science, 31(2), 405-424, doi:10.1080/13658816.2016.1211282.

Zinner, T., H. Mannstein, and A. Tafferner (2008), Cb-TRAM: Tracking and monitoring severe convection from onset over rapid development to mature phase using multichannel Meteosat-8 SEVIRI data, Meteorology and Atmospheric Physics, 101(3-4), 191-210, doi:10.1007/s00703-008-0290-y.

Zuidema, P., B. Baker, Y. Han, J. Intrieri, J. Key, P. Lawson, S. Matrosov, M. Shupe, R. Stone, and T. Uttal (2005), An Arctic Springtime Mixed-Phase Cloudy Boundary Layer Observed during SHEBA, Journal of the Atmospheric Sciences, 62(1), 160-176, doi:10.1175/JAS-3368.1. 
Table 1. Mean difference in effective radius considering three different cases: all tracked clouds, clouds with $r_{e}^{L i q}$ greater than $r_{e}^{i c e}$ at the phase transition, and clouds with $r_{e}^{L i q}$ smaller than $r_{e}^{i c e}$ at the phase transition. The table shows the differences in effective radius before and after the phase transition $\left(\Delta r_{e}^{L i q, I c e}\right)$, the difference between the liquid effective radius two time steps before the phase transition and the liquid effective radius one time step before the phase transition $\left(\Delta r_{e}^{L i q}=r_{e}^{L i q}\left(t_{0}-2\right)-r_{e}^{L i q}\left(t_{0}-1\right)\right.$ with $t_{0}$ the reference time), and the difference between the ice effective radius one time step after the phase transition and the ice effective radius two time steps after the phase transition $\left(\Delta r_{e}^{I c e}=r_{e}^{I c e}\left(t_{0}+1\right)-r_{e}^{I c e}\left(t_{0}+2\right)\right)$

\begin{tabular}{lcccc}
\hline & Nb clouds & $\Delta r_{e}^{\text {Liq, Ice }}(\mu m)$ & $\Delta r_{e}^{\text {Liq }}(\mu m)$ & $\Delta r_{e}^{\text {Ice }}(\mu m)$ \\
\hline All tracked clouds & 230 & -0.2 & 2.3 & 1.3 \\
$r_{e}^{L i q} \geqslant r_{e}^{I c e}$ & 113 & -8.6 & 4.6 & 2.8 \\
$r_{e}^{L i q}<r_{e}^{I c e}$ & 117 & 9.6 & 0.32 & -0.6 \\
\hline
\end{tabular}



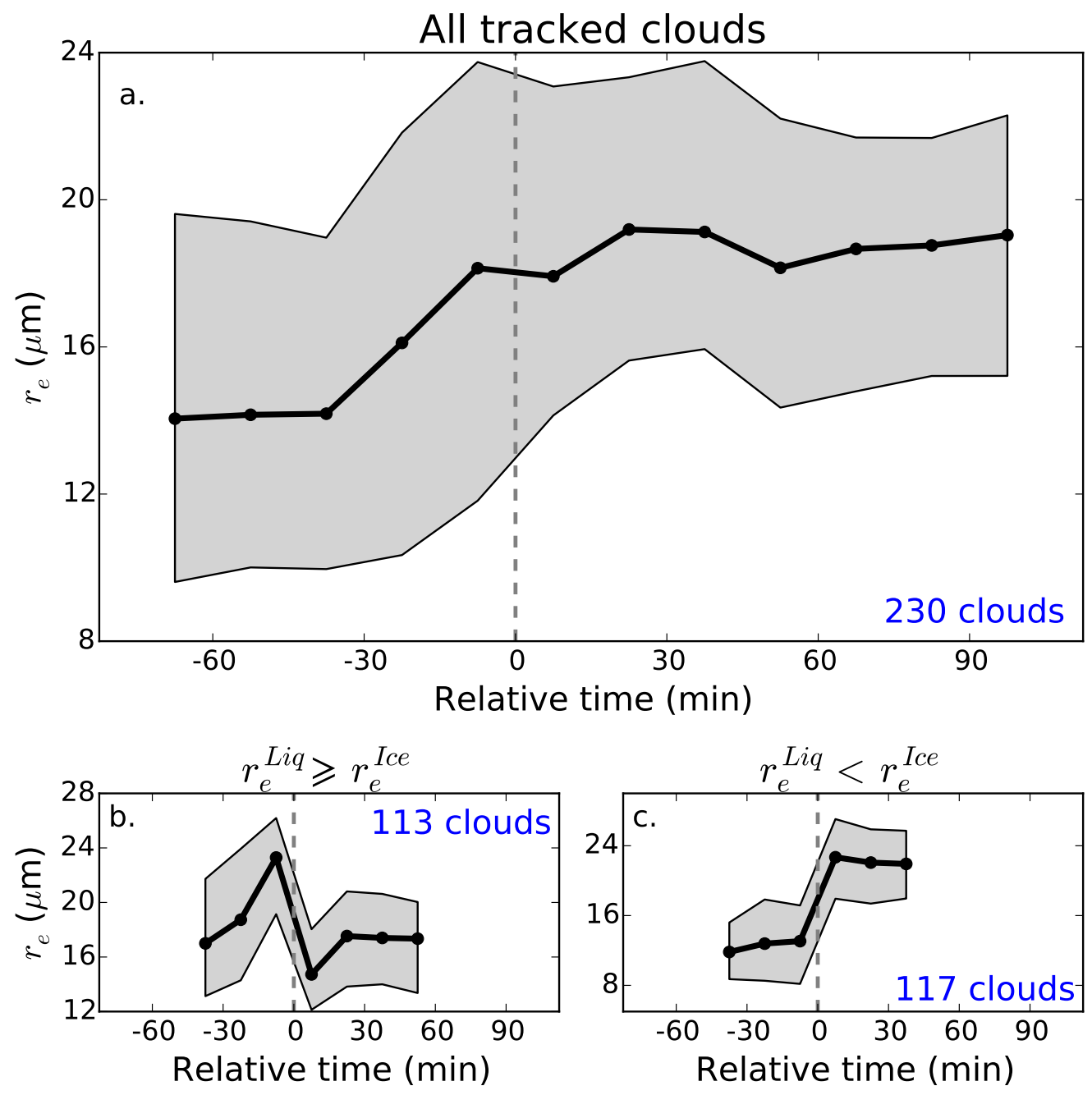

Figure 1. Temporal variations of the effective radius $\left(r_{e}\right)$ at the cloud phase transition. Subfigures a, b, and $\mathrm{c}$ represent the evolution of the coldest-pixel $r_{e}$ of tracked clouds as a function of a relative time for which the reference time is determined by the phase transition in the coldest pixel. Three cases are considered: $r_{e}$ evolution for all tracked clouds (a), $r_{e}$ evolution when $r_{e}^{L i q}$ is larger than $r_{e}^{I c e}$ at the phase transition (b), and when $r_{e}^{\text {Liq }}$ is lower than $r_{e}^{I c e}$ at the phase transition (c). For (a), (b), and (c), the black lines show the median of $r_{e}$ for each time step when at least 70 clouds are tracked - corresponding to $30 \%$ of the entire dataset. The gray areas are delimited by the lower and upper quartiles and the blue numbers indicate how many clouds are tracked in each cases. 

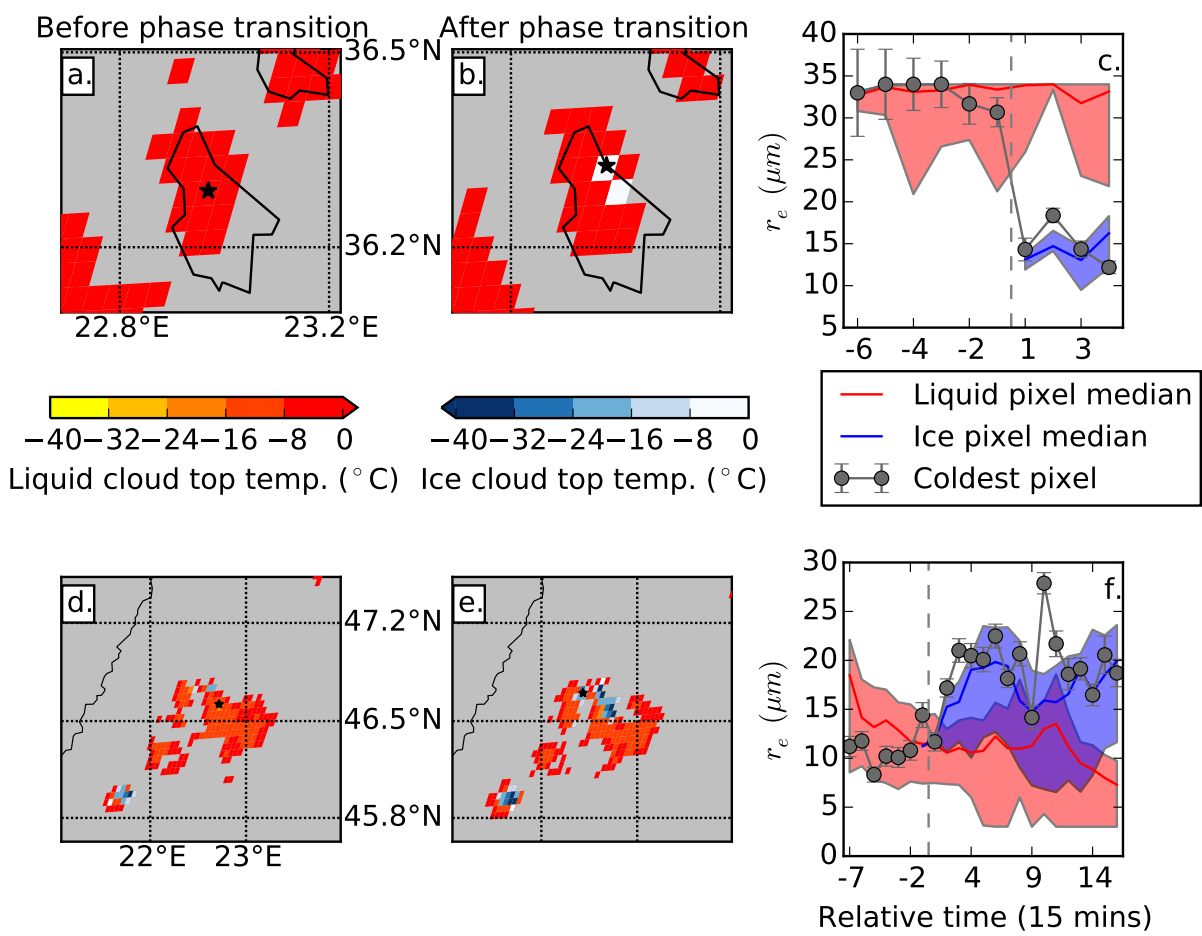

Figure 2. Two cases of cloud phase transition from the $19^{\text {th }}$ of September $2012(a, b, c)-$ case 1 - and the $12^{\text {th }}$ of August $2015(\mathrm{~d}, \mathrm{e}, \mathrm{f})$ - case 2 - are shown. Subfigures a and d show the top temperature of the tracked clouds before the phase transition and subfigures $b$ and e show the top temperature of the tracked clouds after the phase transition. The coldest pixel is indicated in subfigures a and b by a black star. Subfigures $\mathrm{c}$ and $\mathrm{f}$ represent the evolution of the effective radius considering the coldest pixel (gray lines) associated with errorbars representing the retrieval uncertainties, the median for the liquid and ice pixels are shown by respectively the red and blue lines. The red and blue areas are delimited by the lower and upper quartile of respectively liquid and ice effective radius. 

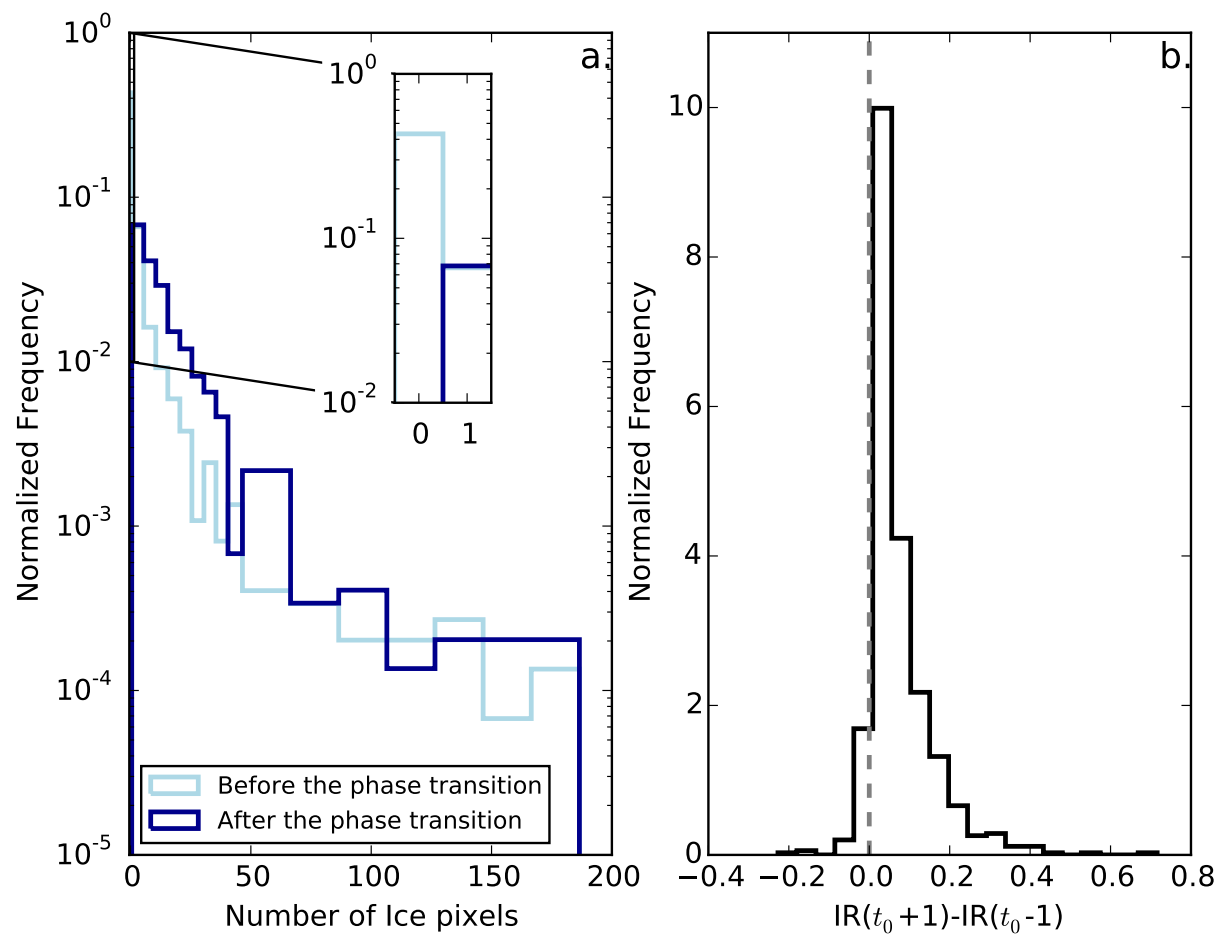

Figure 3. Temporal evolution of ice pixel number at the phase transition. Subfigure a shows the normalized frequency of the number of ice pixels before and after the phase transition. Subfigure b shows the normalized distribution of the difference between the ice ratio after the phase transition and the ice ratio before the phase transition, with the ice ratio defined as the number of ice pixels divided by the number of ice and liquid pixels. The time difference between the two time steps is 15 minutes. 


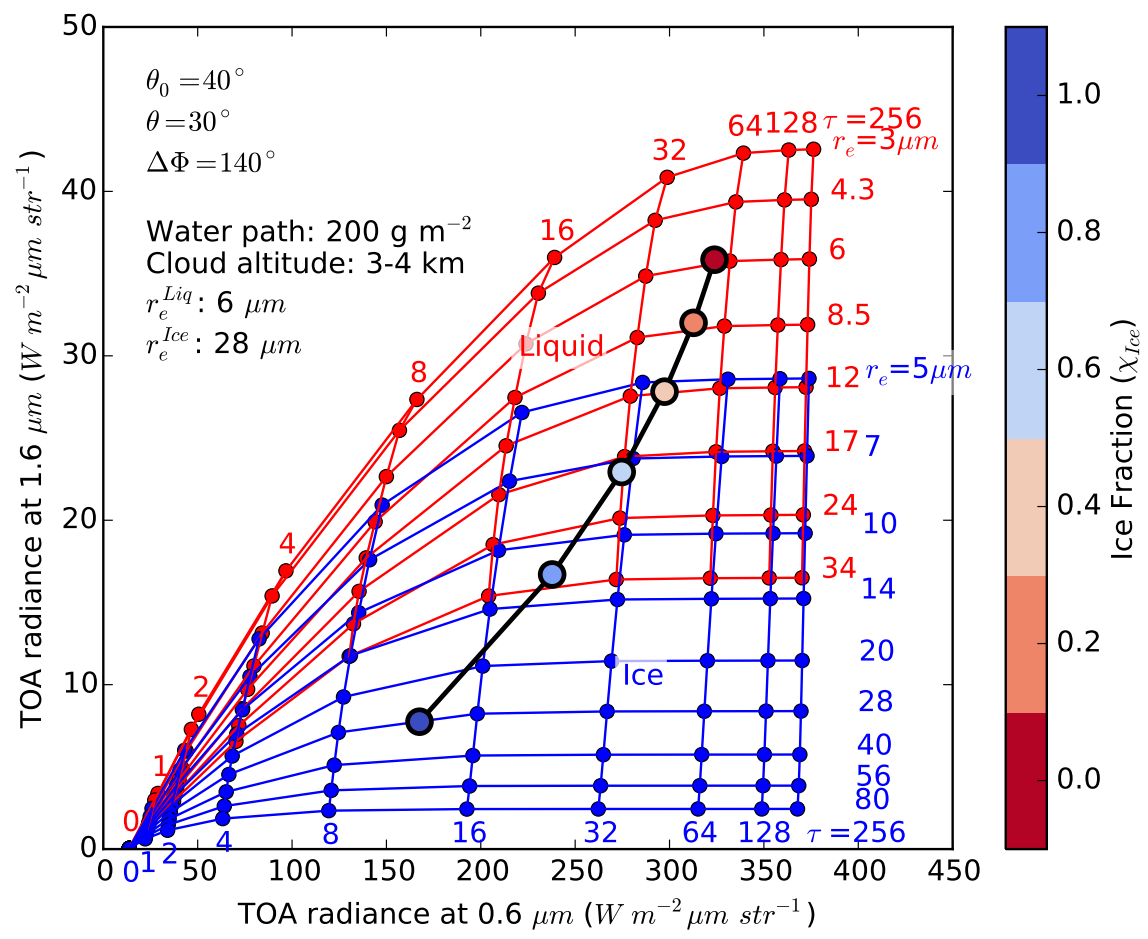

Figure 4. Nakajima \& King diagram considering the radiances at 1.6 and $0.6 \mu \mathrm{m}$ for ice and liquid clouds inferred from radiative transfer simulations. The colored dots represent the radiances for a cloud (with a constant water path at $200 \mathrm{~g} \mathrm{~m}^{-2}$ ) for which different ice fractions are prescribed (see colorbar). Cloud base and top are respectively at 3 and $4 \mathrm{~km}$, and the effective radius of liquid and ice are respectively equal to 6 and $28 \mu m$. 


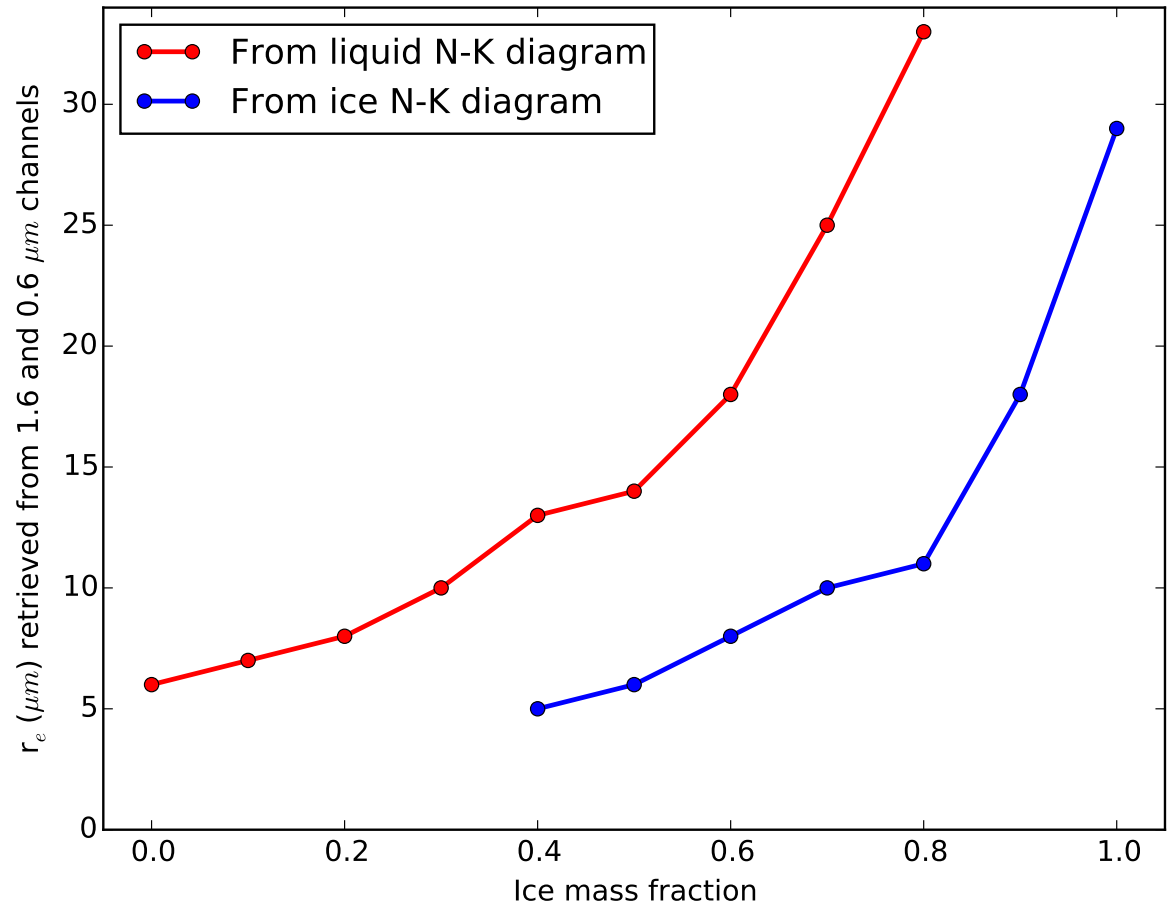

Figure 5. Cloud particle effective radius simulated by the 0.6 and $1.6 \mu \mathrm{m}$ channels as a function of the ice fraction considering whether the cloud is liquid (red) or ice (blue) on the Nakajima \& King diagram simulated by SBDART. Viewing properties and cloud properties are similar to Figure 4. $r_{e}^{\text {Ice }}$ is not represented for ice fraction below 0.4 because the values would have been outside of the Nakajima \& King diagram used by CLAAS-2, $r_{e}^{I c e}$ can range from 5 to $80 \mu m$. Similarly, $r_{e}^{L i q}$ is not represented for ice fraction greater than 0.8 because the values would have been outside of the Nakajima \& King diagram used by CLAAS-2, $r_{e}^{\text {Liq }}$ can range from 3 to $34 \mu m$. 

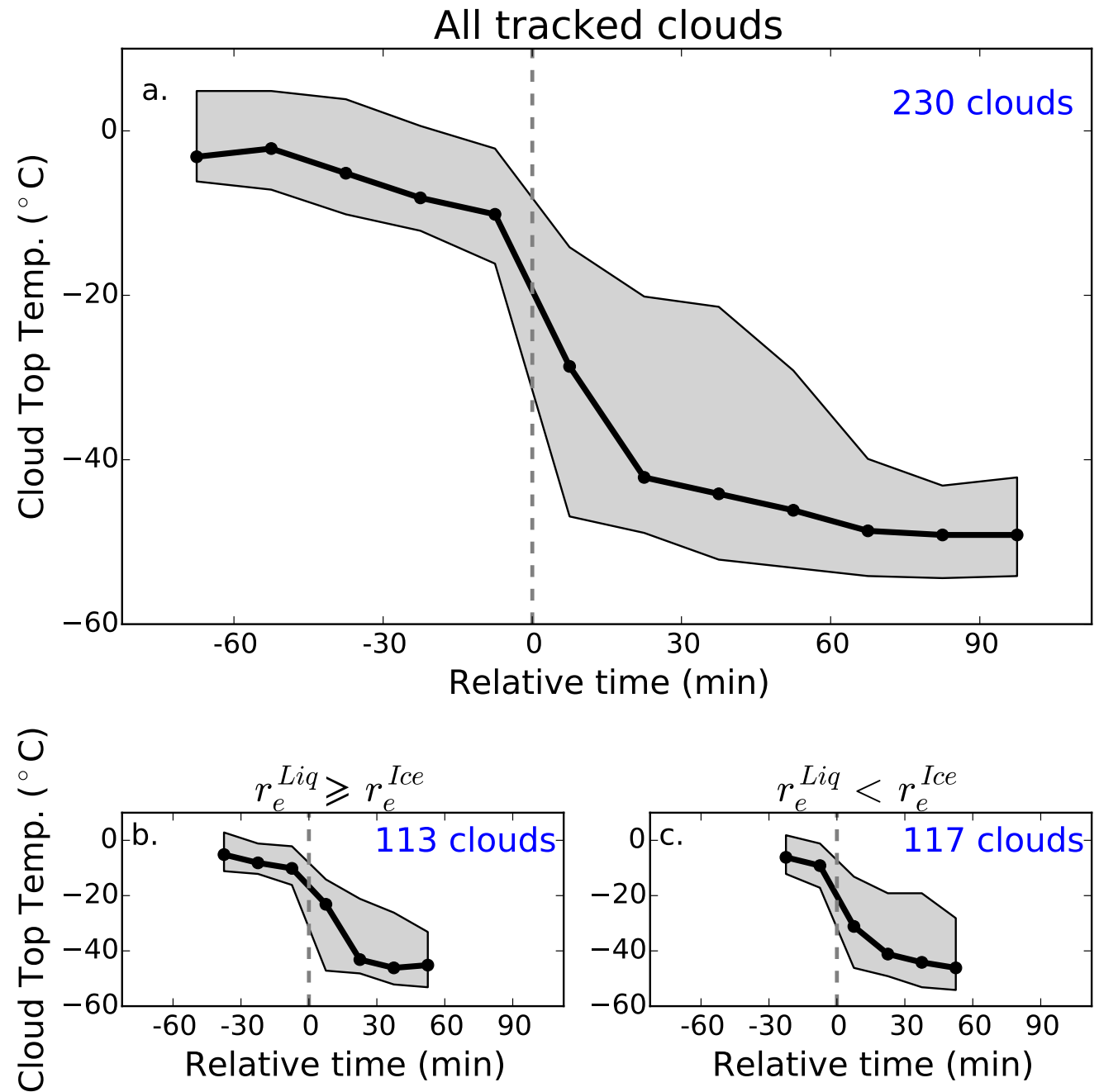

Figure 6. Temporal variations of the cloud top temperature at the cloud phase transition. Subfigures a, b, and $\mathrm{c}$ represent the evolution of the coldest-pixel cloud top temperature of tracked clouds as a function of a relative time. The reference time is determined by the phase transition in the coldest pixel. Three cases are considered: Cloud top temperature evolution for all tracked clouds (a), cloud top temperature evolution when $r_{e}^{L i q}$ is larger than $r_{e}^{I c e}$ at the phase transition (b), and when $r_{e}^{L i q}$ is lower than $r_{e}^{I c e}$ at the phase transition (c). For (a), (b), and (c), the black lines show the median of the cloud top temperature for each time step when at least 70 clouds are tracked - corresponding to $30 \%$ of the entire dataset. The gray areas are delimited by the lower and upper quartiles and the blue numbers indicate how many clouds are tracked in each cases. 